\title{
Por uma gestão mais democrática na educação: contribuições de uma formação a distância para atuação profissional de seus egressos
}

\author{
For more democratic management in education: contributions \\ of a distance formation for the professional performance of its graduates
}

\author{
Daniela Karine Ramos ${ }^{1}$ \\ ${ }^{1}$ Universidade Federal de Santa Catarina | Departamento de Metodologia de Ensino \\ Florianópolis | SC | Brasil. Contato: dadaniela@gmail.com \\ http://orcid.org/
}

Fabiana Lopes Ribeiro ${ }^{2}$

${ }^{2}$ Universidade Federal de Santa Catarina | Centro de Ciências da Educação

Florianópolis | SC | Brasil. Contato: fabigor@gmail.com

http://orcid.org/

Resumo: Este estudo tem como objetivo avaliar as contribuições de um curso de extensão a distância na atuação profissional dos seus egressos no que diz respeito às ações de implantação e/ou fortalecimento dos Conselhos Escolares. Para tanto, realizou-se um levantamento de campo com abordagem quantitativa e qualitativa, por meio da aplicação de um questionário, o que resultou na análise das respostas de 1143 participantes. Os resultados evidenciaram que $64 \%$ dos cursistas colocaram em prática ações planejadas durante o curso e aqueles que realizaram as ações perceberam melhor aproveitamento do curso e maior aprendizagem. A partir disso, reforça-se a importância de políticas e ações de formação continuada que prezem pela relação entre teoria e prática para melhoria da qualidade da educação.

Palavras-chave: Conselho escolar. Gestão democrática da escola. Educação à distância.

Abstract: This study evaluates the contributions of a distance extension course in the professional performance of the graduates with respect to the implementation actions and / or strengthening of the School Councils. For that, a field survey was carried out with a quantitative and qualitative approach, through the application of a questionnaire, which resulted in the analysis of the responses of 1113 participants. The results showed that $64 \%$ of the students put into practice actions planned during the course and those who performed the actions perceived better use of the course and greater learning. From this, the importance of continuing education policies and actions that enhance the relationship between theory and practice to improve the quality of education is reinforced.

Key words: Council. Educational management. Distance education.

DOI: http://dx.doi.org/10.1590/S1414-40772019000300011

Este é um artigo publicado em acesso aberto sob uma licença Creative Commons

https://creativecommons.org/licenses/by-nc/4.0/ 


\section{Introdução}

Qualquer ação realizada por um governo que tenha como objetivo assegurar direitos constitucionais pode ser considerado política pública, sem perder de vista que o essencial é ter como objetivo responder a um problema público (SECCHI, 2010). Neste estudo o problema refere-se ao fortalecimento das ações para consolidação da gestão democrática para melhoria da qualidade da educação, por meio da proposição de uma formação continuada a distância.

Muitas pesquisas sobre as políticas públicas de formação continuada foram realizadas no Brasil nos últimos anos (BACKES et al., 2002; GATTI, 2008; GÉGLIO, 2015). Essas pesquisas apresentaram enfoques diversos, mas o relevante para o presente estudo diz respeito às intencionalidades, às metodologias utilizadas e aos resultados dos processos formativos, mais especificamente no que diz respeito à formação continuada e a educação a distância.

O estudo avalia indicadores de eficácia de uma das ações de formação a distância do Programa Nacional de Fortalecimento dos Conselhos Escolares (PNFCE) criado pela Portaria Ministerial $n^{\circ} 2.896 / 2004$, o qual tem dentre seus objetivos, ampliar a participação das comunidades escolar e local na gestão das escolas públicas e apoiar ações para implantação e fortalecimento de Conselhos Escolares (BRASIL, 2004).

Dentre as ações previstas no programa destaca-se a oferta de cursos a distância para formação de multiplicadores vinculados as secretarias de educação e pessoas que atuam nos conselhos escolares. Neste estudo, analisa-se o curso a distância de Formação Continuada em Conselhos Escolares (FCCE), realizado em parceria com Instituições Federais de Ensino Superior (IFES) e o Ministério da Educação (MEC), para formação de técnicos das secretarias de educação estaduais e municipais para o fortalecimento da gestão democrática em suas regiões, por meio do planejamento e atuação em ações de implantação e fortalecimento dos Conselhos Escolares (RAMOS, 2015). Nas IFES a formação caracteriza-se como um projeto de extensão.

De modo geral, as questões que permeiam a formação continuada, bem como todo o PNFCE, dizem respeito à melhoria da qualidade da educação básica em nosso país, por meio da gestão democrática. O programa propõe a criação e o fortalecimento dos Conselhos Escolares, que são espaços de tomada de decisões de maneira coletiva na escola, entendidos como órgãos colegiados "que têm como atribuição deliberar sobre questões políticopedagógicas, administrativas, financeiras, no âmbito da escola” (BRASIL, 2004, p. 34).

Quanto à oferta do curso, temos 14 Instituições Federais de Ensino Superior (IFES) que atenderam de maneira regionalizada a quase todo território nacional, por meio da organização, 
divulgação, seleção dos cursistas, oferta e certificação. Entre 2009 e 2014, os cursos ofertaram quase 40 mil vagas, de acordo com relato da coordenação do programa, tendo formado aproximadamente 25 mil pessoas.

Os cursos se estruturam de maneira semelhante em muitos aspectos nas diferentes IFES, especialmente no que se refere ao material didático, à carga horária e às atividades obrigatórias de levantamento de dados (Plano Inicial) e o planejamento de ações para solução de problemas, apresentado ao final do curso, denominado Plano de Ação.

O curso de FCCE foi estruturado a partir de ambientes virtuais de aprendizagem, como a plataforma MOODLE, por exemplo. Cada uma das fases do curso contempla o estudo de materiais didáticos com temáticas específicas elaborados pela Secretaria de Educação Básica (SEB) do MEC. Existe uma recomendação para que na Fase 1, correspondente a 100 horas de estudo, sejam estudados os cadernos de 1 a 6 e, na Fase 2, mais 100 horas, os cadernos de 7 a 12, em virtude do caráter complementar do material. As temáticas dos cadernos tendem a seguir uma linha crescente de aprofundamento sobre as questões referentes ao Conselho Escolar e sua relação com o cotidiano da escola. Dentre as temáticas dos cadernos, destacam-se questões sobre democratização, aprendizagem, aproveitamento significativo do tempo pedagógico, valorização da cultura, formação humana, escolha do diretor, financiamento da educação, educação no campo, dentre outros.

Além do estudo dos cadernos e das atividades propostas sobre eles, que cada IFES teve autonomia para elaborar, outras duas atividades obrigatórias compuseram a avaliação do cursista ao final de cada fase, o Plano Inicial e Plano de Ação. O Plano Inicial é uma atividade obrigatória do curso a ser realizada no final da primeira fase, cujo objetivo é a realização de um levantamento sobre alguns aspectos do contexto em que o cursista atua. Trata-se, portanto, de uma sistematização de informações, como uma espécie de diagnóstico, que servirá de base para a elaboração do Plano de Ação, atividade obrigatória para a segunda fase do curso (RAMOS, 2015). Com a elaboração do Plano de Ação, é esperado que o cursista identifique os "desafios e possibilidades para a criação, consolidação e fortalecimento dos conselhos escolares nas redes de ensino estaduais e municipais" (RAMOS, 2015, p. 6), no intuito de que se instrumentalize para atuar na articulação de tais ações. Essa atividade é composta de várias etapas, nas quais serão abordados os itens a seguir:

a. Problema e Diagnóstico do Problema: contempla a descrição do(s) problema(s) levantado(s) a partir do diagnóstico realizado nas atividades anteriores (plano inicial); b. Proposta de ação: descreve a(s) ação(ões) proposta(s) para o(s) problema(s) levantado(s); c. Objetivos da ação: descreve os objetivos a serem atingidos para resolução do(s) problema(s) levantado(s); d. Procedimentos da ação: descreve de forma detalhada os procedimentos necessários para a operacionalização da ação 
proposta, observando os objetivos definidos; e. Cronograma da ação: organiza as ações num espaço de tempo, prevendo a operacionalização da ação proposta; $f$. Acompanhamento da ação: descreve os procedimentos para o acompanhamento da operacionalização da proposta e de seus resultados (RAMOS, 2015, p. 6).

Com relação ao Plano de Ação, a atividade visava a entrega de um trabalho escrito sobre uma proposta de atuação. A atuação em si, não era atividade do curso, apenas figurou como recomendação, até porque a colocação em prática de tais planejamentos iria de encontro aos objetivos do curso de FCCE e do próprio PNFCE. Esse aspecto ressalta a importância de investigar a percepção dos egressos sobre essa atividade.

Levando em consideração as especificidades do processo formativo, destaca-se como questão norteadora do estudo: Considerando a percepção e avaliação dos egressos, quais foram as contribuições do curso de FCCE para a atuação profissional dos seus egressos? Para responder essa questão se faz necessário observar alguns aspectos referentes ao curso e às políticas públicas das quais ele faz parte, bem como os aspectos relacionados à modalidade em que o curso foi ofertado e sua influência nas contribuições percebidas pelos egressos, sem tampouco perder de vista o perfil desse egresso.

Diante disso, tem-se como objetivo analisar as contribuições do curso de Formação Continuada em Conselhos Escolares para a atuação profissional de seus egressos. Mais especificamente, trata-se de avaliar as contribuições do curso de FCCE para atuação profissional dos egressos no que diz respeito às ações de implantação e/ou fortalecimento dos Conselhos Escolares nas redes de ensino/municípios, tomando como principal indicador a aplicação do plano de ação construído no processo de formação continuada a distância.

\section{Educação a Distância a Avaliação com Egressos}

A Educação a Distância (EAD) caracteriza-se, sobretudo, pela flexibilidade espaçotemporal e pelo uso das tecnologias digitais (BELLONI, 2009; SEVERINO et al., 2011), constituindo-se uma alternativa de formação para muitas pessoas que, por razões diversas, não possuem acesso à educação tradicional (BUFORD, 2005; MOORE; KEARSLEY, 2008). De modo geral, a EAD revela-se uma forma conveniente para adultos que precisam conciliar a aprendizagem com outras prioridades sociais, laborais e familiares (POZDNYAKOVA; POZDNYAKOV, 2017; CHOI; PARK, 2018).

Além das características do público da EAD, vários fatores do próprio curso podem afetar o processo de ensino e aprendizagem. Segundo Moore e Kearsley (2008), temos fatores como a relevância do conteúdo para a carreira ou interesses do aluno, a mediação e o grau de apoio; as tecnologias utilizadas para acesso aos conteúdos e interação, o acompanhamento e os 
feedbacks relacionados ao avanço no curso e as interações entre professor, tutores e outros alunos.

Alguns autores tentaram definir esses alunos prevalecendo o entendimento sobre a importância da autonomia para o sucesso do aprendente da EAD (MOORE; KEARSLEY, 2008; PALLOFF; PRATT, 2004; BELLONI, 2009). Esse e outros fatores relacionados ao aluno da EAD instigam a seguir investigando os egressos dos cursos a distância, considerando a relevância do perfil e o contexto dos alunos para o seu sucesso, bem como a opinião deles sobre os aspectos do curso que gerem contribuições práticas em suas carreiras profissionais e/ou pessoais, visto que "o levantamento do perfil dos alunos pode oferecer alguns indicativos sobre esses fatores e orientar a discussão, a reflexão e a busca de alternativas para solucionar problemas enfrentados" (RAMOS, 2013, p. 204).

Ao considerarmos os alunos, destacamos que os estudos realizados com egressos, oferecem evidências em relação a aspectos e fatores que permitem avaliar os cursos. Assumese que essas pesquisas tendem a ter um potencial de mudar significativamente as formações em questão. Para Meira e Kurcgant (2009), por exemplo, a opinião dos egressos sobre sua formação é fundamental na concretização de um sistema de avaliação que construa um processo educativo com características emancipatórias e transformadoras. Também Cislaghi et al. (2015) apresentam conclusões semelhantes, pois, para eles, o acompanhamento dos concluintes traz informações significativas para apoiar a gestão quanto à melhoria dos cursos, podendo resultar em currículos mais focados e qualificados.

Algumas características apresentadas pelos alunos tendem a interferir em sua satisfação após a realização dos cursos online. Segundo Kuo et al. (2014), os egressos que se disseram mais autônomos para realizar o curso sentiram-se mais satisfeitos com a formação. Também outros estudos apontaram que fatores como mais experiência com o uso do computador e maior disposição para utilizar novas tecnologias parecem gerar maior satisfação aos egressos dessas formações (SOUZA et al., 2015; NASCIMENTO; RAMOS; OLIVEIRA JUNIOR, 2011).

A partir de métodos e perspectivas diferentes, a grande maioria dos trabalhos da amostra apresenta dados positivos com relação às formações a distância quando avaliadas pelos seus estudantes egressos. Muitos dizem ter aprendido (ANDRONIC et al., 2012; COLARES; BRYAN, 2014; SOUZA et al., 2015, FERRUGINI; CASTRO, 2015) e, inclusive, há relatos sobre melhoria da atuação prática dos egressos após a realização do curso, a partir do emprego dos conhecimentos adquiridos (COLARES; BRYAN, 2014). Os cursos online também apresentaram benefícios no que diz respeito ao aumento da capacidade de argumentação e ao desenvolvimento do senso crítico dos seus egressos (FERRUGINI; CASTRO, 2015). 


\section{Metodologia}

A pesquisa realizada caracteriza-se como um levantamento de campo, com abordagem quantitativa e qualitativa por trabalhar com dados estatísticos e a descrição de fenômenos concretos em interação dinâmica na tentativa de significar ações e relações humanas.

\subsection{Participantes}

Os sujeitos da pesquisa são os egressos dos cursos de FCCE de 12 Instituições Federais de Ensino Superior parceiras do Ministério da Educação na oferta do curso de extensão a distância. A amostra constituiu-se por conveniência, por meio de e-mail encaminhado ao coordenador do Programa Nacional de Fortalecimento dos Conselhos Escolares na SEB/MEC, que replicou os questionários aos coordenadores dos cursos nas IFES e esses encaminharam a seus egressos. Não há dados sobre a quantidade de egressos que receberam as solicitações para preenchimento dos questionários, tampouco temos confirmação de que todos os coordenadores enviaram as solicitações aos seus egressos.

No momento inicial da análise somavam 1143 respostas ao questionário encaminhado pelos egressos, tendo sido, contudo, excluídas algumas respostas de acordo com critérios como: negativas ao termo de consentimento livre esclarecido $(n=5)$; respostas duplicadas de um mesmo participante $(n=18)$; erros ou incoerências nas respostas $(n=7)$. A partir disso, tivemos um total de 1113 respostas válidas consideradas para análise.

No que se refere à idade dos 1113 egressos participantes da pesquisa, identificamos que $44 \%$ tem entre 42 e 51 anos, $30 \%$ tem entre 31 e 41 anos, $20 \%$ tem entre 52 e 61 anos, $4 \%$ tem entre 18 e 30 anos, e $2 \%$ tem entre 62 e 71 anos. Com relação ao sexo dos egressos que responderam à pesquisa, foi possível identificar que $84 \%$ é do sexo feminino e $16 \%$ é do sexo masculino.

\subsection{Instrumentos e procedimentos}

A partir da revisão de literatura e mapeamento de pesquisas relacionadas procedeu-se a elaboração da primeira versão do questionário. Esta foi submetida a um pré-teste, por meio da aplicação com 5 pessoas que atuam na educação e em seguida dialogou-se sobre a compreensão das questões, escala, organização e dificuldades para responder ao instrumento. A partir disso, realizaram-se ajustes no instrumento.

O questionário incluiu aspectos relacionados ao perfil dos egressos, com questões sobre o sexo, idade, escolaridade, atuação profissional, experiência prévia na EAD, autonomia para 
aprender, tempo de estudo, dentre outras. Tais aspectos foram fatores que poderiam na análise ser relacionados a situações facilitadoras ou não do aprendizado no decorrer do curso, bem como influenciar a percepção sobre a sua eficácia, visto que a satisfação do aluno com um curso a distância pode ter relação inclusive com a sua autonomia para estudar (KUO et al., 2014).

Optou-se por elaborar um questionário quanti-qualitativo, com questões objetivas e abertas. Nas questões objetivas sobre a aquisição de conhecimentos pautou-se na apresentação de afirmações para analisar o nível de concordância, por meio do uso da escala de Likert. As questões foram divididas em cinco tópicos temáticos, com quatro afirmações cada uma (Quadro 1). Os tópicos foram divididos com o intuito de ampliar a compreensão sobre as possíveis contribuições da formação.

\section{Quadro 1}

Também, no questionário propôs-se uma questão discursiva sobre as principais contribuições do curso para a atuação profissional do egresso, juntamente com uma questão sobre as dificuldades enfrentadas pelo egresso com relação a modalidade e, por fim, os egressos foram questionados sobre a colocação ou não de seus Planos de Ação em prática e quais as razões para tal.

\subsection{Análise dos dados}

A maior parte dos dados caracterizou-se como quantitativos e puderam ser tabulados utilizando o software "Excel”, por meio do qual foi possível filtrar os dados, transformando-os em números e legendas, podendo gerar gráficos e tabelas. Em seguida foram analisados utilizado o software SPSS (Statistical Package for the Social Sciences) versão 23.0 para análise estatística. Investigou-se a associação entre a percepção da aprendizagem nos diferentes tipos de conhecimentos abordados no curso e a aplicação do plano de ação, por meio do teste " $t$ de student" para amostras independentes, atribuindo-se o intervalo de confiança de $95 \%$.

Já fatores como experiência prévia na EAD; autonomia para aprender, tempo de estudo, atuação profissional e tempo de atuação foram analisados pela estatística descritiva, destacando-se a frequência de cursistas em cada item que colocaram em prática o plano de ação.

Os dados qualitativos, mais especificamente as questões relacionadas às dificuldades da educação a distância, à aplicação do Plano de Ação e às principais contribuições do curso de 
FCCE na atuação profissional dos egressos, foram analisados utilizando o software NVivo11 para análise qualitativa e relacional.

A análise dos dados qualitativos utilizou-se das técnicas de análise de conteúdo baseadas nas teorias de Bardin (2011), procedendo-se inicialmente a leitura flutuante de todo o material para, na sequência, iniciar a codificação utilizando o software.

\section{Resultados e discussão sobre as contribuições do curso para atuação profissional dos egressos}

O Plano de Ação, atividade obrigatória para completar a segunda fase do curso de FCCE, visava o planejamento e organização de uma ação prática para fomentar a implantação ou o fortalecimento dos Conselhos Escolares. Entendendo a importância da relação entre teoria e prática, bem como a necessidade de planejamento das ações a serem realizadas, tal trabalho tinha um diferencial, pois se embasa na atividade denominada Plano Inicial realizada na primeira fase do curso, considerada um diagnóstico do município de atuação do cursista. Assim, incentivava-se que no plano de ação, o cursista propusesse uma solução a um problema encontrado em seu município ou rede de ensino, relacionado com a gestão democrática e a atuação dos Conselhos Escolares.

A implementação do Plano de Ação não era tarefa do curso, visto que a exigência era apenas a entrega de um trabalho escrito, figurando apenas como uma recomendação implícita, atentando-se à relevância da concretização do trabalho. Ao analisarmos os dados referentes ao Plano de Ação, foi possível identificar uma relação estreita entre o aproveitamento dos cursistas e a aplicação prática do trabalho. Conforme os dados estatísticos, o fator "aplicação do Plano de Ação" (observado na tabela 1) apresenta resultados significativos para todos os quesitos ( $p<0,0001)$, sendo possível inferir que os sujeitos que aplicaram seus Planos de Ação tiveram uma maior percepção sobre sua aprendizagem e seu aproveitamento do curso.

\section{Tabela 1}

Tendo em vista que o Plano de Ação era uma atividade obrigatória da Fase 2 do curso de FCCE, então, apenas $74 \%$ dos egressos, o que soma um total de 822 sujeitos, estariam aptos a fazê-lo, por terem cursado as duas fases do curso. Desses, $64 \%$ afirmaram terem colocado seu Plano de Ação em prática após terem terminado o curso, totalizando 522 egressos, e os demais $36 \%$, um total de 300 egressos, afirmaram que não. 
A colocação em prática das ações previstas no Plano de Ação pode ser tomada como um indicativo da efetividade da formação à distância, visto que concretizaria seu objetivo de fortalecimento da gestão democrática por meio de ações que visariam a implantação e o fortalecimento dos Conselhos Escolares. Pode-se ressaltar a importância da atividade de construção do Plano de Ação para a concretização da práxis, tão relevante aos processos de formação continuada. Segundo Luiz et al. (2010, p. 91):

o curso possibilitou a esses alunos vincular conteúdos teóricos (amadurecidos durante os estudos dos dez cadernos do Ministério da Educação [...] sobre conselhos escolares e discussões teóricas nos fóruns), e práticos (vivenciado por cada cursista), com perspectiva de construir ações baseadas em suas realidades.

Grumiché (2014) em seu estudo analisou as temáticas dos Planos de Ação dos cursistas da segunda fase do curso de FCCE, oferecido pela UFSC no ano de 2013 e, de acordo com seus achados, é possível dividir as temáticas dos planos em quatro grupos. O primeiro voltado para ações de criação e implantação do Conselho Escolar, valorizando a cultura de participação nos municípios em que atuavam; o segundo focava no fortalecimento da participação dos integrantes dos Conselhos Escolares já implantados, especialmente dos pais, visando uma maior aproximação entre escola e família; o terceiro voltava-se para ações que buscavam ampliar ações de formação continuada junto aos Conselhos Escolares já existentes e o último relacionado à criação de legislações municipais pertinentes à necessidade de formação e qualificação dos Conselhos Escolares (GRUMICHÉ, 2014).

Essas ações retratam questões pertinentes a atuação dos conselhos escolares que figuram como um exemplo da grande abrangência e das possibilidades que a realização dessa atividade apresenta e o quão relevante é entender as questões que favoreceram ou dificultaram a sua aplicação prática.

Algumas relações foram possíveis de serem estabelecidas entre a aplicação do Plano de Ação e alguns aspectos relacionados aos egressos, como a sua autonomia para aprender, o seu tempo de estudo, a sua atuação profissional e o seu tempo de atuação na área da educação. Esses fatores foram capazes de influenciar a atuação prática dos egressos, sendo facilitadores ou impeditivos para a concretização dos objetivos do curso.

No que se refere aos respondentes que se consideraram autônomos para aprender, foi possível relacionar essa autonomia à aplicação do Plano de Ação. Percebemos que, dentre os sujeitos que se dizem autônomos para aprender, é maior a porcentagem dos que colocaram seus planos de ação em prática, em comparação com o grupo que se percebe como não apto a aprender sozinho, conforme gráfico 1 . 


\section{Gráfico 1}

A relação entre o fator "autonomia para aprender" e o sucesso do aluno também aparece em outras pesquisas, como por exemplo, Kuo et al. (2014), que afirmam que os egressos que se disseram mais autônomos, sentiram maior satisfação com relação à sua aprendizagem. Seus estudos se basearam em aspectos de interação, da autoeficácia e de autorregulação da aprendizagem, indicando que esses aspectos têm forte influência na percepção de sucesso dos egressos.

Ainda com relação à aplicação do Plano de Ação, foi possível identificar que o tempo de estudo influenciou diretamente na colocação desse plano em prática ou não. Pode-se observar que conforme aumenta o tempo dedicado aos estudos, maior é o percentual de participantes que colocaram o plano de ação em prática.

\section{Gráfico 2}

A relação com o tempo é uma questão recorrente na $\mathrm{EAD}$, como evidenciado no estudo de Ramos (2013) em que identificou que umas das principais dificuldades dos alunos dos cursos de graduação a distância de uma universidade federal era a falta de tempo para dedicar-se aos estudos. Isso por que os alunos da EAD são, em geral, adultos com família e ainda dedicam grande parte do seu tempo as atividades profissionais (BUFORD, 2005). Esse fator tempo precisa ser considerado por ser uma dificuldade e porque como se observa nos resultados pode ser associado ao melhor desempenho e envolvimento no curso, já que se evidenciou que quanto mais tempo dedicado ao curso maior o percentual de cursistas que colocam o plano de ação em prática.

Além do tempo de estudo, observa-se que a própria atuação profissional influenciou na aplicação do Plano de Ação. Conforme o gráfico 3, uma grande porcentagem de cursistas que se dizem gestores, num total de 71,49\%, indicam ter colocado seus Planos de Ação em prática. Enquanto a média de aplicabilidade do trabalho pelas demais categorias ficou em torno de $65 \%$.

\section{Gráfico 3}

Essa questão vem corroborar com a ideia de que por vezes a não aplicação do Plano de Ação não se deu por falta de capacitação do cursista egresso, mas, sim, por questões externas relacionadas à autonomia para atuar num contexto complexo como o da educação pública. 
A aplicação do plano de ação, associada à atuação profissional, remetem as próprias condições para a formação dos cursistas, as quais podem contribuir para motivação e maior significação da aprendizagem. Esse aspecto reforça que a educação de adultos pode ser entendida em alguns contextos como uma alternativa para a aquisição de novos conhecimentos e habilidades necessárias para lidar com as mudanças e desafios da atuação profissional (TITMUS, 2014).

A relação entre o tempo de atuação e a aplicação do Plano de Ação também foi percebida, visto que, conforme aumenta o tempo de atuação do cursista, maior a porcentagem de indivíduos que alegam ter colocado seu trabalho em prática. Esse fato pode remeter a autonomia adquirida por anos de atuação como algo importante para a efetividade da atuação do egresso em ações de implantação e de fortalecimento dos Conselhos Escolares.

\section{Gráfico 4}

A análise da aplicação do plano de ação recebeu destaque neste estudo por se um importante indicador de que a processo de formação ofereceu repercussões para atuação profissional e, consequentemente, evidencia que os objetivos do curso foram atingidos. Além disso, atividades como a elaboração do plano de ação, partindo da análise da realidade e seus problemas, exige que os alunos elaborem e compartilhem suas experiências anteriores, o que facilita uma aprendizagem mais profunda e significativa (BUFORD, 2005).

Após a identificação do perfil dos egressos que mais aplicaram seus Planos de Ação, o próximo passo foi identificar os porquês de alguns egressos terem conseguido aplicar seus trabalhos e outros não.

Diante disso, analisamos e criamos categorias a partir das falas dos egressos que não aplicaram seus Planos de Ação, descritas na tabela 2, indicando uma multiplicidade de justificativas, que nos ajudam a ampliar a compreensão sobre os motivos e dificuldades para maior articulação entre os conhecimentos adquiridos e a efetivação de uma ação em sua realidade.

Tabela 2

Destaca-se que a principal justificativa, com $25 \%$ do total das respostas, refere-se a não atuação na área responsável pelas ações de implantação e fortalecimento dos Conselhos Escolares em seu município ou rede de ensino. Alguns alegaram não atuarem mais na área, 
outros disseram atuar em outros setores da Secretaria de Educação. Muitos se dizem afastados ou não atuando em escola, também alguns disseram nunca ter atuado com a especificidade do curso. Enfim, esse fator foi a justificativa mais recorrente para a não efetivação do seu planejamento e também pode ser levado em conta no planejamento de outros cursos e seleção de cursistas.

Alguns cursistas, mais precisamente $11 \%$ do total de respondentes, ainda que tenham alegado que seu Plano de Ação não foi colocado em prática, afirmaram que essa aplicação está em andamento. Como é o caso do cursista 919, que afirma que seu plano "ainda está em fase de mobilização".

A falta de oportunidade foi a reclamação de $9 \%$ do total de respondentes, alegando que não conseguiram aplicar seus Planos de Ação. Dentro dessa categoria se enquadram falas como as seguintes: "A atual gestão não é aberta a gestão democrática" (Cursista153); ou "não tive campo e nem autonomia para implantar meus conhecimentos" (Cursista 653); e "não tenho autonomia para executar este procedimento" (Cursista 946).

Alguns Planos de Ação foram aplicados parcialmente, conforme afirmam 7\% do total dos respondentes, denotando certa efetividade, visto que, ainda que a ação não tenha sido completada, algumas sementes foram plantadas, como ressalta o cursista 562: "Não totalmente, na minha Unidade escolar conseguimos a implantação do conselho, porem a rede ainda não são todas as Unidades que implantaram”. Também essa mesma porcentagem de egressos diz que a realização do Plano de Ação auxiliou de outra maneira, conforme afirma o cursista 92:

A mediação dos conhecimentos e as dinâmicas apresentadas no Curso construíram um engajamento sócio-político propulsor de desejo por mudança, transformação, aplicação e etc., todavia, as barreiras são muitas, assim como, a inércia de pessoas que apresentam resistência às mudanças. Mas, não desisto e a cada dia procuro persuadir a experimentar possibilidades que favoreçam o coletivo (Cursista 92).

Em alguns contextos, a existência dos Conselhos Escolares foi impeditiva para a aplicação do Plano de Ação, conforme o relato de 7\% dos respondentes. De acordo com as falas, com os Conselhos Escolares consolidados não haveria oportunidade ou razão para a aplicação do seu Plano de Ação, conforme afirma o Cursista 48: "Não porque já existiam os conselhos consolidados. Existe todo um regimento já estabelecido e uma sistemática implantada, o que não permitiu a colocação".

A falta de interesse, tanto por parte da escola, dos gestores ou da Secretaria de Educação, ficou evidente na fala de $6 \%$ dos respondentes que não conseguiu colocar seus Planos de Ação em prática. Questões políticas também foram determinantes para a não aplicação, de acordo com 5\% dos egressos. Segundo o cursista 555: “Quando fiz o curso era técnica da Secretaria de 
Educação; por questões políticas os técnicos não são aproveitados quando não concordam com a Administração Pública, retornando à sua função de origem, sem qualquer aproveitamento da sua formação".

Vários foram utilizados como justificativas, mas, de modo geral, destacou-se a falta de compromisso dos municípios com os Conselhos Escolares; o fato de o Plano de Ação ter sido apenas atividade do curso sem que tenha havido pretensão de aplicá-lo; a falta de tempo; a falta de apoio da Secretaria de Educação; a existência de um plano anterior; a falta de estrutura; as muitas dificuldades encontradas; a necessidade de ajustes no Plano; a falta de planejamento; e, finalmente, o trabalho ainda estar em análise.

O cursista 141, por exemplo, alega que seu:

"plano de ação foi construído individualmente, apesar de ter feito pensando nos Conselhos Escolares do meu município ninguém nunca viu e ficou apenas como atividade do curso. O curso e a prática eram fragmentados. Houve tentativa de fortalecimento na prática, mas por poucas pessoas e durou pouco teтро”.

Ainda que a percepção sobre as contribuições do curso na atuação prática permeiem as falas de vários egressos, como se pode ver, isso não é consenso.

De outro modo, os egressos que alegaram terem colocado seus Planos de Ação em prática, as respostas reforçam, sobretudo, a valorização do papel do Conselho Escolar e da relevância em trazer a comunidade para escola. Os relatos descritos evidenciam que houve sensibilização e modificações nas práticas dos egressos após a realização do curso, com repercussões nas suas redes de ensino. Em pesquisas apresentadas por Gatti (2008), também foi possível observar que, após a realização da formação continuada, os egressos apresentaram mudanças de postura com relação à suas escolhas e também mudanças nas suas práticas.

Exemplos de tais mudanças podem ser vistos quando o cursista 35 afirma "construímos a lei da gestão democrática e implantamos os conselhos municipais em todas as escolas do município", denotando uma ação prática realizada. Ou mesmo por meio de novas ideias, como por exemplo, quando o cursista 61 diz que "surgiram novas formas de trabalhar com a comunidade", bem como o surgimento do sentimento de segurança para agir que a aparece na fala do cursista 93, que aponta que "com a formação me senti segura para partilhar desses conhecimentos e implementar no município". Essas reações e ações são implicações do curso na atuação profissional e também na vida dessas pessoas, denotando contribuições práticas importantes do curso de FCCE por meio da realização da atividade Plano de Ação.

Levando em conta os relatos mobilizados, é possível afirmar que as contribuições na atuação prática dos egressos de fato ocorreram. Tanto os dados qualitativos como os 
quantitativos são positivos, visto que 64\% dos egressos alegaram terem colocado seus Planos de Ação em prática e, dentre os que dizem não ter colocado, uma grande porcentagem diz que está em andamento ou foi aplicado parcialmente.

Dessa forma, reforça-se a importância desses processos de formação como formas de atualizar os conhecimentos dos seus alunos, permitindo que reflitam sobre suas práticas e encontrem saídas para os conflitos do dia a dia escolar (COLARES; BRYAN, 2014).

\section{Considerações Finais}

O estudo realizado propôs-se a analisar o processo de formação a distância dentro de uma política pública, procurando evidências da efetivação dos objetivos para além de números de concluintes, buscando indicativos sobre o que esse processo promoveu de mudanças no contexto de atuação de seus participantes. Para tanto, tomou-se a implantação do plano de ação elaborado no curso como um forte indicativo de que a experiência e o conhecimento adquiridos fomentaram a realização de ações concretas no campo de atuação.

Além disso, destacamos alguns fatores que puderam ser associados ao fato de colocar em prática o plano de ação, como a autonomia para aprender, o tempo dedicado aos estudos e o tempo de atuação profissional, por exemplo.

Ressalta-se que o presente estudo evidenciou a aplicação do plano de ação, como relevante para o sucesso de um processo de formação continuada à distância, por promover, sobretudo, a relação entre a teoria e a prática. Todavia, entende-se que outros fatores, como os conteúdos, as tecnologias e a mediação, também são essenciais para o sucesso de processos formativos na modalidade.

Por fim, ao consideramos a abrangência do curso e quantidade de participantes, podemos entender que este processo de formação gerou um movimento em que centenas de pessoas que, após terem participado do curso, se envolveram em ações para a implantação e o fortalecimento dos Conselhos Escolares em todo país. Pessoas que por iniciativa própria partiram da atividade realizada durante o processo de formação para a realização das ações de implantação e fortalecimento dos Conselhos Escolares nas suas redes de ensino. 


\section{Referências}

ANDRONIC, Răzvan-lucian et al. Opinions about Distance Learning in Romania. A comparative research. Procedia - Social And Behavioral Sciences, EUA, v. 69, n. 1, p.21512155, dez. 2012.

BACKES, Vânia Marli Schubert et al. A educação continuada dos alunos egressos: compromisso da universidade? Revista brasileira de enfermagem, Brasília, v. 55, n. 2, p. 200-204, fev. 2002.

BARDIN, Laurente. Análise de conteúdo. São Paulo: Edições 70, 2011.

BELLONI, Maria Luiza. Educação a distância. 5. Ed. Campinas, SP: Autores Associados. 2009.

BRASIL. Ministério da Educação. Secretaria de Educação Básica. Programa Nacional de Fortalecimento dos Conselhos Escolares. Conselhos escolares: uma estratégia de gestão democrática na escola pública. Brasília: MEC, SEB, 2004.

BUFORD, James. An introduction to designing and delivering courses and programs at a distance. In: DOOLEY, Kim E. et al. Advanced methods in distance education: applications and practices for educators, administrators, and learners. London: IGI Global, 2005.

CHOI, Hee Jun; PARK, Ji-Hye. Testing a path-analytic model of adult dropout in online degree programs. Computers \& Education, EUA, v. 116, p. 130-138, 2018.

CISLAGHI, Renato et al. Gestão de qualidade de cursos a partir da percepção de estudantes egressos. Revista Renote: Novas Tecnologias na Educação, Porto Alegre, v. 13, n. 1, p.1-10, jul. 2015.

COLARES, Maria Lilia Imbiriba Sousa; BRYAN, Newton Antonio Paciulli. Formação continuada e gestão democrática: desafios para gestores do interior da Amazônia. ETD Educação Temática Digital, Campinas, SP, v. 16, n. 1, p. 174-191, abr. 2014.

FERRUGINI, Lílian; CASTRO, Cleber Carvalho de. Repercussões socioeconômicas do curso piloto de administração da UAB na visão de egressos e coordenadores. Educ. Pesqui., São Paulo, v. 41, n. 4, p.993-1008, dez. 2015.

GATTI, Bernadete Angelina. Análise das políticas públicas para formação continuada no Brasil, na última década. Revista Brasileira de Educação, Rio de Janeiro, v. 13, n. 37, p. 5770, abr. 2008.

GÉGLIO, Paulo César. Políticas públicas de formação continuada para professores: um estudo de cursos realizados a partir de propostas licitatórias. Ensaio: Avaliação e Políticas Públicas em Educação, Rio de Janeiro, v. 23, n. 86, p. 231-257, fev. 2015. 
GRUMICHÉ, Mônica. "Plano de Ação": uma análise registrada da realidade. In: RAMOS, Daniela K. (Org.). Conselho Escolar e Gestão Democrática: contribuições de uma formação para a cidadania. Nova Petrópolis: Nova Harmonia, 2014. p. 137-159.

KUO, Yu-chun et al. Interaction, Internet self-efficacy, and self-regulated learning as predictors of student satisfaction in online education courses. The Internet And Higher Education, EUA, v. 20, p. 35-50, jan. 2014.

LUIZ, Maria Cecília et al. Indicadores de funcionamento do conselho escolar em alguns municípios paulistas. In: LUIZ, Maria Cecília (org.). Conselho escolar: algumas concepções e propostas de ação. São Paulo: Xamã, 2010.

MEIRA, Maria Dyrce Dias; KURCGANT, Paulina. Avaliação de curso de graduação segundo egressos. Revista da Escola de Enfermagem da USP, São Paulo, v. 43, n. 2, p.481-485, jun. 2009.

MOORE, Michael G., KEARSLEY, Greg. Educação a distância: uma visão integrada. São Paulo: Cengage Learning, 2008.

NASCIMENTO, Thiago Cavalcanti; RAMOS, Anatália Saraiva Martins; OLIVEIRA JÚNIOR, Paulo César Medeiros de. Prontidão tecnológica e satisfação de alunos na modalidade a distância: o caso de um programa de capacitação de um governo estadual. Rege, São Paulo, v. 18, n. 3, p.489-509, set. 2011.

PALLOFF, Rena M.; PRATT Keith. O aluno virtual. Um guia para trabalhar com estudantes on-line. Porto Alegre: Artmed, 2004.

POZDNYAKOVA, Oksana; POZDNYAKOV, Anatoly. Adult Students' Problems in the Distance Learning. Procedia Engineering, EUA, v. 178, p. 243-248, 2017.

RAMOS, Daniela Karine. Perfil dos alunos de licenciatura a distância e aspectos que contribuem para aprendizagem. Revista Reflexão e Ação, Santa Cruz do Sul, v. 21, n. 2, p. 199-220, 2013.

RAMOS, Daniela Karine (org.). Guia do Aluno. Curso de Extensão a Distância Formação Continuada em Conselhos Escolares. Florianópolis: UFSC, 2015.

SECCHI, Leonardo. Políticas públicas: conceitos, esquemas de análise, casos práticos. São Paulo: Cengage Learning, 2010.

SEVERINO, Fabio et al. Distance education: the role of self-efficacy and lócus of control in lifelong learning. Procedia Social and Behavioral Sciences, EUA, v. 28, 2011, p. 705-717.

SOUZA, Geisa Colebrusco de et al. Avaliação do curso de gerenciamento online na perspectiva dos egressos. Revista da Escola de Enfermagem da USP, São Paulo, v. 49, n. spe2, p.90-97, dez. 2015.

TITMUS, Colin J. (ed.). Lifelong education for adults: an international handbook. New York: Elsevier, 2014. 
No PDF do artigo Por uma gestão mais democrática na educação: contribuições de uma formação a distância para atuação profissional de seus egressos com número de DOI: 10.1590/S1414-40772019000300011, publicado no periódico AVALIAÇÃO, 24 (3): 766-784, na página 772, no terceiro parágrafo onde se lê Quadro 1, deve-se incluir:

\begin{tabular}{|c|c|}
\hline \multirow{4}{*}{$\begin{array}{l}\text { Implantação dos } \\
\text { Conselhos Escolares }\end{array}$} & $\begin{array}{l}\text { Após ter feito o curso de Formação em Conselhos Escolares participei do } \\
\text { processo de implantação do(s) Conselho(s) Escolare(s) }\end{array}$ \\
\hline & $\begin{array}{l}\text { O curso de formação me motivou a fomentar e incentivar a implantação do(s) } \\
\text { Conselho(s) Escolare(s) }\end{array}$ \\
\hline & $\begin{array}{c}\text { No curso de formação aprimorei conhecimentos e habilidades que foram } \\
\text { utilizadas (ou poderiam ser utilizadas) em ações para implantação do(s) } \\
\text { Conselho(s) Escolare(s) }\end{array}$ \\
\hline & $\begin{array}{l}\text { O curso de formação me qualificou para os procedimentos referentes à } \\
\text { regulamentação dos conselhos escolares em minha rede de ensino/município }\end{array}$ \\
\hline \multirow{4}{*}{$\begin{array}{l}\text { Fortalecimento dos } \\
\text { Conselhos Escolares }\end{array}$} & $\begin{array}{l}\text { Após o curso de formação propus e/ou participei de ações para o fortalecimento } \\
\text { dos Conselhos Escolares na minha rede de ensino e/ou município }\end{array}$ \\
\hline & $\begin{array}{c}\text { No curso de formação adquiri competências necessárias para a tarefa de contribuir } \\
\text { com o fortalecimento dos Conselhos Escolares na minha rede de ensino e/ou } \\
\text { município }\end{array}$ \\
\hline & $\begin{array}{l}\text { Após curso me senti mais seguro(a) para orientar ações, participar de discussões e } \\
\text { incentivar iniciativas que venham (ou poderiam vir) a fortalecer a atuação dos } \\
\text { Conselhos Escolares }\end{array}$ \\
\hline & $\begin{array}{c}\text { As atividades de levantamento de informações sobre os conselhos (plano inicial) e } \\
\text { o plano de ação auxiliaram (ou poderiam auxiliar) na execução de ações para a } \\
\text { implantação e/ou fortalecimento dos conselhos escolares. }\end{array}$ \\
\hline \multirow{4}{*}{$\begin{array}{l}\text { Sobre os conhecimentos } \\
\text { adquiridos no curso }\end{array}$} & $\begin{array}{l}\text { No curso de formação pude aprender os conceitos básicos sobre os Conselhos } \\
\text { Escolares }\end{array}$ \\
\hline & $\begin{array}{c}\text { No curso de formação pude aprender questões práticas sobre os Conselhos } \\
\text { Escolares }\end{array}$ \\
\hline & $\begin{array}{l}\text { Os materiais e atividades do curso de formação me ajudaram na ampliação dos } \\
\text { conhecimentos sobre os Conselhos Escolares }\end{array}$ \\
\hline & $\begin{array}{l}\text { Os feedbacks recebidos no curso de formação me ajudaram a ampliar o } \\
\text { conhecimento sobre os Conselhos Escolares }\end{array}$ \\
\hline \multirow{4}{*}{$\begin{array}{l}\text { Sobre a iniciativa de } \\
\text { formação continuada/ } \\
\text { divulgação }\end{array}$} & $\begin{array}{l}\text { Realizar o curso de Formação Continuada em Conselhos Escolares me motivou a } \\
\text { realizar outras formações na modalidade à distância }\end{array}$ \\
\hline & $\begin{array}{c}\text { Recomendaria o curso de Formação Continuada em Conselhos Escolares a um } \\
\text { colega }\end{array}$ \\
\hline & $\begin{array}{l}\text { Após o curso passei a compartilhar mais informações sobre os Conselhos } \\
\text { Escolares e divulgar as políticas e ações relacionadas ao Programa }\end{array}$ \\
\hline & $\begin{array}{l}\text { Em virtude da participação no curso de formação, me tornei a/o principal } \\
\text { responsável pelo Programa Nacional de Fortalecimento dos Conselhos Escolares } \\
\text { em minha instituição e/ou município }\end{array}$ \\
\hline \multirow{4}{*}{ Sobre o Plano de Ação } & $\begin{array}{l}\text { A elaboração do Plano de Ação me auxiliou na implantação e/ou fortalecimento } \\
\text { dos Conselhos Escolares em minha rede de ensino }\end{array}$ \\
\hline & $\begin{array}{l}\text { A elaboração do Plano de Ação me fez refletir sobre as necessidades de ter os } \\
\text { Conselhos Escolares atuantes na minha rede de ensino }\end{array}$ \\
\hline & $\begin{array}{l}\text { Realizar o Plano de Ação foi crucial para minha atuação na implantação e/ou } \\
\text { fortalecimento dos Conselhos Escolares em minha rede de ensino }\end{array}$ \\
\hline & A elaboração do Plano Inicial me auxiliou na construção do Plano de Ação \\
\hline
\end{tabular}


Na página 773, onde se lê Tabela 1, deve-se incluir:

\begin{tabular}{|c|c|c|c|c|}
\hline Escores & $\begin{array}{c}\text { Média } \\
\text { Sim (DP) }\end{array}$ & $\begin{array}{c}\text { Média } \\
\text { Não (DP) }\end{array}$ & $t$ & $p$ \\
\hline Implantação & $15,95(4,78)$ & $13,37(4,96)$ & 8,71 & $0,00 * *$ \\
\hline Fortalecimento & $17,98(2,30)$ & $15,43(3,75)$ & 13,96 & $0,00^{* * *}$ \\
\hline Conhecimento & $18,53(1,82)$ & $17,70(2,58)$ & 6,27 & $0,00^{* * *}$ \\
\hline Compartilhamento & $16,83(2,68)$ & $14,32(3,49)$ & 13,54 & $0,00 * *$ \\
\hline Plano de Ação & $17,09(2,99)$ & $12,17(5,67)$ & 18,73 & $0,00^{* * *}$ \\
\hline Total & $86,37(10,65)$ & $72,99(14,90)$ & 17,46 & $0,00 * *$ \\
\hline
\end{tabular}

Na página 775, onde se lê Gráfico 1, deve-se incluir:

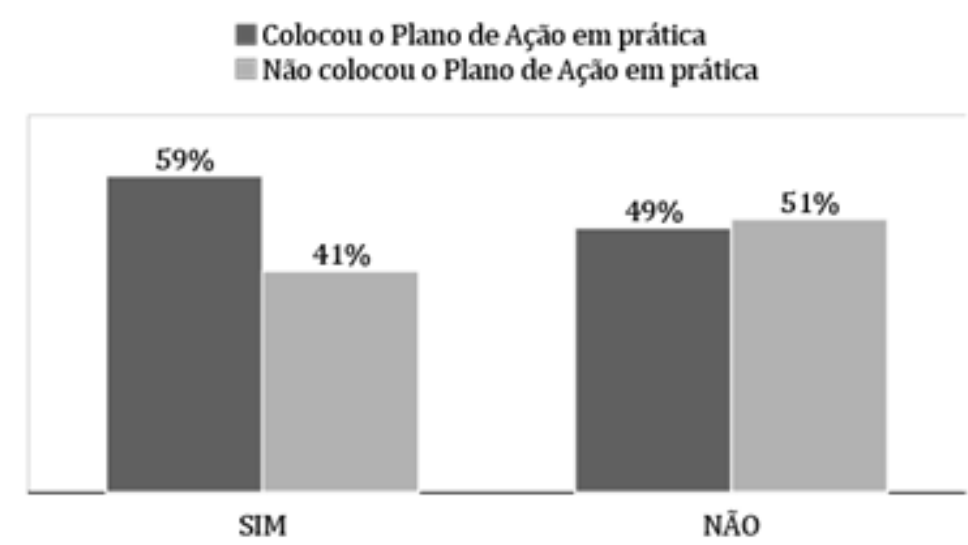

Na mesma página, onde se lê Gráfico 2, deve-se incluir:

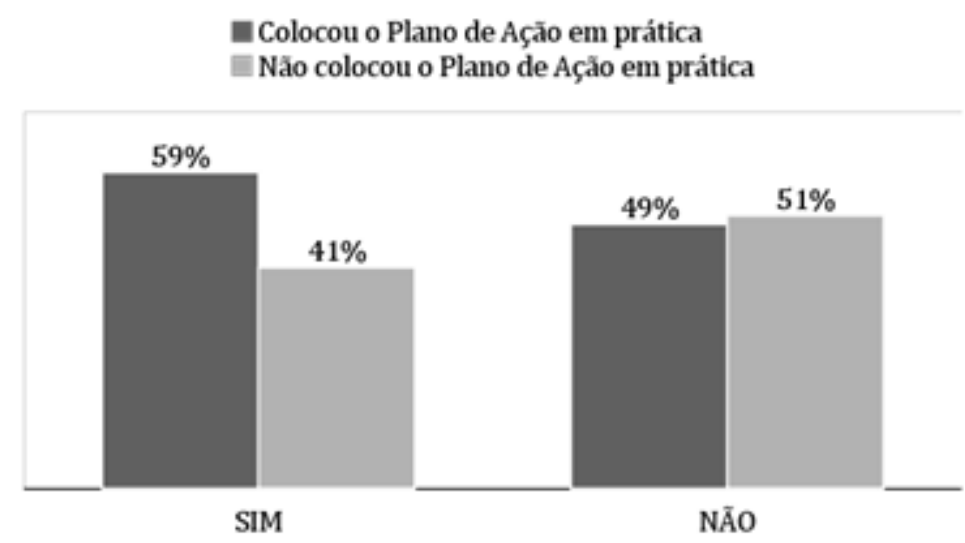


Ainda na mesma página, onde se lê: Gráfico 3, deve-se incluir:

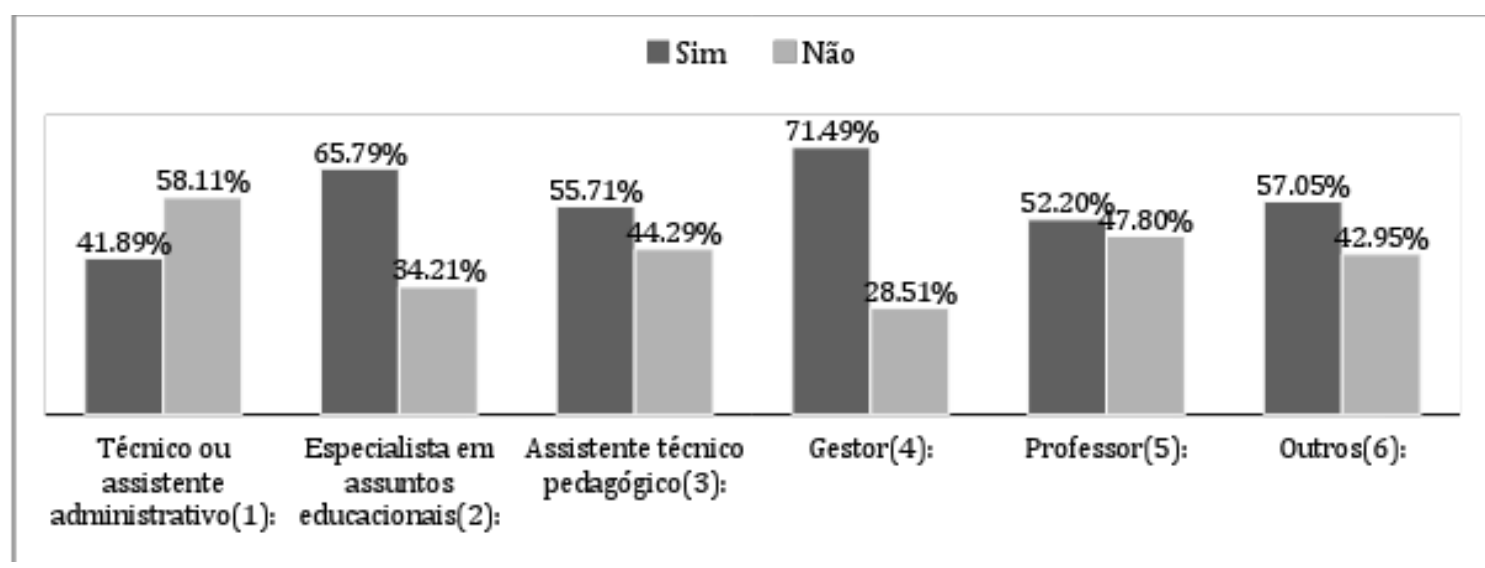

Na página 776, onde se lê Gráfico 4, deve-se incluir:

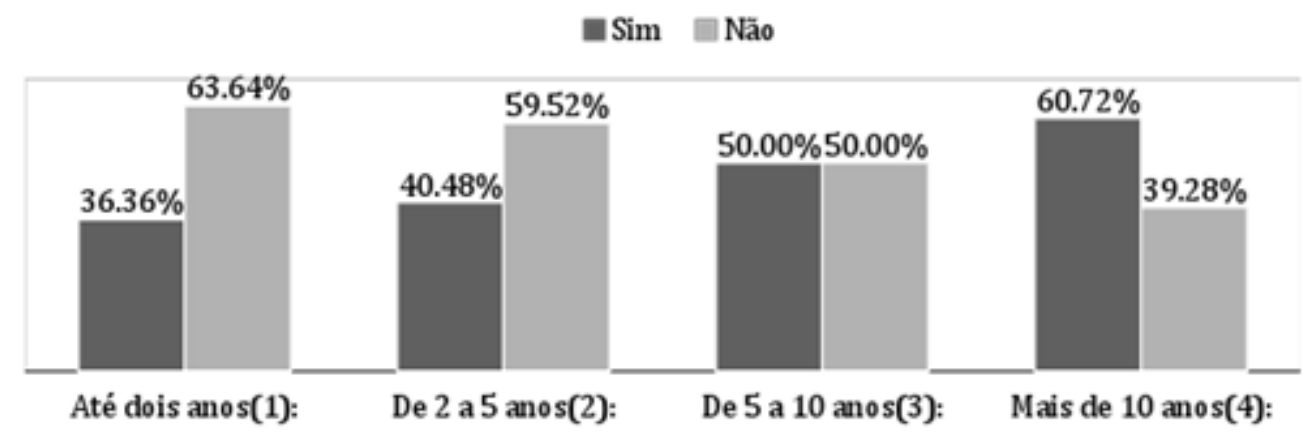

Na mesma página, onde se lê Tabela 2, deve-se incluir:

\begin{tabular}{ccc}
\hline Justificativas & Frequência & Percentual \\
\hline Não atua na área & 103 & $25 \%$ \\
Em andamento & 47 & $11 \%$ \\
Não teve oportunidade & 37 & $9 \%$ \\
Aplicado parcialmente & 30 & $7 \%$ \\
Auxiliou no desenvolvimento de outra ação & 30 & $7 \%$ \\
Já existiam conselhos & 29 & $7 \%$ \\
Não houve interesse & 26 & $6 \%$ \\
Questões políticas & 21 & $5 \%$
\end{tabular}


Falta de compromisso dos municípios

Foi apenas atividade do curso

Falta de tempo

Não recebeu apoio da secretaria de educação

Já existia um plano anterior

$2 \%$

Não tinha estrutura suficiente

$2 \%$

Muitas dificuldades encontradas

$2 \%$

Precisa de alguns ajustes

$1 \%$

Outras

$7 \%$ 